\title{
Cancer survivors get new office
}

Although victory cannot be declared in the war against cancer, some battles are being won, demonstrated by the increasing number of long-term survivors. According to recent US National Cancer Institute (NCI) studies, all types of cancer have seen increases in five-year survival rates since 1960, although some types show more modest gains than others. According to $\mathrm{NCI}$ director Richard Klausner, the increase in survival rates has brought "a wonderful conundrum": a new set of challenges and problems for surviving cancer patients. To help meet those challenges, Klausner recently opened the Office of Cancer Survivorship (OCS). Anna Meadows, professor of pediatric oncology at the University of Pennsylvania Medical School, has been appointed the new office's first director.

"The idea behind the new office is to support and coordinate any research that might be helpful to individuals who are cancer survivors," says Meadows, who was the first oncologist to conduct follow-up studies in the 1970 s and 1980 s with pediatric leukemia patients who had received cranial radiation. Her prior research experience will strongly influence the direction OCS will take: Predisposition to secondary cancers, the effects of drugs and radiation given at certain ages to particular parts of the body, infertility and organ damage following anticancer treatment, as well as a host of psychosocial issues, are a few of the areas the new office will examine, said Meadows.

The OCS is not the first organization to study cancer survivors: an international consortium of 13 cancer institutions, organized by Meadows in 1974 with the help of NCI funding, holds that distinction. A program at the University of Minnesota, set up five years ago, tracks some 20,000 childhood cancer survivors from the standpoints of health, employment, offspring, risk-taking behaviors, family history and predisposition to cancer, and secondary cancers. However, OCS's is the largest such effort to date.

Planned research at OCS will fall into roughly two categories: outcomes to which survivors are subject (economic and psychological outcomes as well as physical) and ways of preventing or lessening the effects of treatment. Meadows projects four types of studies: retrospective studies of individuals who have survived cancer for 30 to 40 years; prospective studies of new patients; studies that correlate molecular and cellular characteristics of tumors with outcome, prognosis, diagnosis, and treatment; and cooperative group studies.

The OCS will also create create a new section in the NCI's Physician Data Query (PDQ) program to incorporate informa- tion addressing the health care provider community about survivorship issues. The goal is to create a multimedia access clearinghouse of information about survivorship.

A cadre of cancer experts from a variety of disciplines will serve as consultants, including geneticists Louise Strong of the M.D. Anderson Cancer Center in Houston and Fred $\mathrm{Li}$ of Boston's Dana Farber Cancer Institute, and psychiatrist Jimmie Holland of New York's Memorial Sloan-Kettering Cancer Center.

VICKI BROWER

New York, New York

\section{France's CNRS goes au naturelle}

The Centre National de la Recherche (CNRS), France's largest public research institute, has formed a new task force dedicated to "natural" products, in line with similar actions taken by other nations. Entitled "Groupement de Recherche (GDR) sur les substances naturelles," the task force is designed to support the collection and study of plants, as well as marine invertebrates, algae and fungi, for possible drug candidates. The network of task force members is drawn from the biomedical institute INSERM, ORSTOM (an organization involved in scientific research in the intertropical zone), and universities and medical centers throughout France.

The primary objectives of GDR are to promote information exchange between scientists scattered throughout the world and to make use of each other's skills. Another GDR goal is improving the training of young chemists, who will not only screen chemical substances found in plants but examine the biological activities of these substances as well.

Screening natural products for active compounds has already proven successful in France, although it is not a well-directed effort. For example, ICSN has released into the market two "natural" products proven effective in the treatment of cancer: Taxotére, a semisynthetic substance whose base molecule comes from the yew leaf (developed in collaboration with the French pharmaceutical company Rhône-Poulenc Rorer), and Navelbine, a compound derived from the Madagascar periwinkle (in collaboration with the Pierre Fabre laboratories, headquartered in Castres).

But such successes are too few in number, according to some experts. Thierry Sévenet of ICSN says it is "time to breathe new life into [a type of] research that has been suffocating in France, in part because many people think that molecular design and combinatorial chemistry will resolve the problems concerning the discovery of new molecules for treating cancer, AIDS and other diseases."

There is a sense of urgency underlying the new project, particularly because other countries such as the United States and Japan have bolstered their own programs. In 1987, for example, the US National Cancer Institute in Bethesda, Maryland, infused its Natural Products Branch with US\$8 million.

Despite the urgency, the Achilles' heel of the GDR might prove to be its small budget. CNRS, itself overwhelmed by a severe money shortage, has for now allocated just US\$20,000 for the project. Sévenet says that is enough to get the network started, but he hopes to supplement it with subsidies from ORSTOM and the Secretary of State for Research, and from contracts between GDR and pharmaceutical companies.

Another major problem to be faced is sorting out relations and legal agreements between the GDR and the producing countries of any natural products of interest. Says Christian Moretti of the Natural Substances Division at ORSTOM, "I would not like us to be accused of looting." CATHERINE TASTEMain Paris, France 